\title{
KAJIAN TINGKAT BAHAYA EROSI UNTUK ARAHAN KONSERVASI TANAH PADA BERBAGAI TIPE PENGGUNAAN LAHAN DI KECAMATAN MERDEKA KABUPATEN KARO
}

\author{
Parlin Hotmartua Putra Pasaribu, Abdul Rauf, Bejo Slamet \\ Program Studi Pengelolaan Sumberdaya Alam dan Lingkungan Pascasarjana USU Medan \\ Jl. Prof. Ma' as Universitas Sumatera Utara, 20155 Indonesia \\ Email : hotmartuapasaribu93@gmail.com
}

\begin{abstract}
Abstrak
Tujuan penelitian ini untuk mengetahui tingkat erosi guna mendapatkan acuan konservasi tanah pada berbagai tipe penggunaan lahan di Kecamatan Merdeka. Penelitian ini menggunakan metode survei analisis prediksi erosi yang dilakukan dengan metode USLE. Hasil penelitian menunjukan bahwa laju erosi tertinggi terdapat pada penggunaan lahan tegalan yaitu sebesar 2.959,018 ton/ha/tahun, sedangkan erosi terendah terdapat pada penggunaan lahan permukiman yaitu sebesar 29,810 ton/ha/tahun. Erosi terbolehkan tertinggi dan terendah terdapat pada penggunaan lahan semak belukar yaitu masing - masing sebesar 36,96 ton/ha/tahun dan 6,81 ton/ha/tahun. Indeks bahaya erosi tertinggi terdapat pada penggunaan lahan Hutan sekunder yaitu sebesar 342 ton/ha/tahun, sedangkan indeks bahaya erosi terendah terdapat pada penggunaan lahan semak belukar yaitu sebesar 1,08 ton/ha/tahun. Ada 3 (tiga) kategori tingkat bahaya erosi di Kecamatan Merdeka yaitu tingkat bahaya erosi level sedang, tinggi, dan sangat tinggi. Teknik konservasi tanah mekanik yang digunakan seperti teras bangku, guludan, saluran penampungan air, saluran pengelak, dan penanaman sejajar kontur sedangkan teknik konservasi vegetatif yaitu seperti tumpang sari, mulsa organik, pengkayaan tanaman keras, pohon serbaguna, kebun campuran, dan tanaman penutup tanah.
\end{abstract}

Kata kunci : Erosi Tanah metode USLE, Indeks Bahaya Erosi, Konservasi Tanah

\begin{abstract}
The purpose of this research is to know the level of erosion to get the reference of soil conservation on various types of land use in Merdeka District. This research used erosion prediction analysis survey method with USLE method. The results showed that the highest erosion rate was found on the using of land, of 2,959,018 tons/ha/ year, while the lowest erosion was found on the use of settlement land of 29,810 tons / ha / year. The highest and lowest permissible erosion was found in the use of scrubland, of 36.96 ton / ha / year and 6.81 tons/ha/ year respectively. The highest erosion hazard index was found in secondary forest land use of 342 tons/ha /year, while the lowest erosion index was 1,08 tons /ha/year. There are 3 (three) categories of erosion hazard in Merdeka District, they are medium, high, and very high erosion level. Mechanical soil conservation techniques are used such as bench terraces, bunds, water reservoirs, ducts, and parallel planting of contours while vegetative conservation techniques such as intercropping, organic mulch, hardwood enrichment, multipurpose trees, mixed gardens, and cover crops.
\end{abstract}

Keywords : Soil Erosion USLE method, Erosion Hazard Index, Soil Conservation 


\section{PENDAHULUAN}

Salah satu sumber daya alam utama yang ada di bumi adalah tanah. Tanah adalah suatu ruang daratan dan merupakan bagian dari lahan yang mempunyai banyak fungsi bagi kehidupan (Makhrawie, 2012). Namun perlu diketahui bahwa tanah sendiri merupakan sumber daya alam yang mudah mengalami kerusakan atau degradasi.

Erosi merupakan salah satu jenis kerusakan lahan. Menurut Yudhistira (2011), erosi merupakan salah satu petunjuk bahwa suatu lahan tersebut mengalami kerusakan. Selanjutnya menurut Anwar (2009), erosi adalah proses terkikisnya dan terangkutnya tanah atau bagian-bagian tanah oleh media alami yang berupa air. Erosi merupakan indikator adanya kesenjangan pada pemanfaatan atau penggunaan lahan di suatu wilayah. Namun perlu diketahui bahwasannya erosi juga dapat terjadi secara alami, yang menjadi masalah adalah erosi yang diakibatkan oleh aktivitas manusia yang dimanfaatkan untuk berbagai keperluan seperti penggunaan lahan untuk pertanian, permukiman dan sebagainya.

Kecamatan Merdeka adalah salah satu Kecamatan di Kabupaten Karo, Sumatera Utara yang merupakan dataran tinggi dengan ketinggian $1.200-1.800$ meter dpl. Luas wilayah Kecamatan Merdeka 2,08 persen dari total luas Kabupaten Karo yaitu sebesar 44,17 Km², dan terdiri dari 9 Desa (BPS Kabupaten Karo, 2016).

Penggunaan lahan di Kecamatan Merdeka sangat beragam mulai dari permukiman, hutan, semak belukar, pertanian dan lain sebagainya. Namun penggunaan lahan pertanian adalah yang paling dominan pemanfaatannya dengan berbagai jenis komoditi tanaman pertanian. Perkembangan atau pertumbuhan masyarakat yang cukup tinggi di wilayah ini mengakibatkan sebagian besar lahan telah dimanfaatkan oleh masyarakat setempat baik untuk pemukiman maupun untuk lahan pertanian. Areal pertanian di Kecamatan ini di dominasi dengan jenis taman sayuran dan buah-buahan serta palawija. Berbagai jenis tanaman tersebut tersebar di Kecamatan Merdeka yang memiliki topografi yang beragam mulai dari yang relatif datar, bergelombang, berbukit sampai bertopografi curam. Pola penanaman dengan jenis tanaman holtikultura tersebut dengan topografi yang curam akan menimbulkan dampak yang serius bagi tanah itu sendiri. Hal tersebut dikarenakan jenis tanaman holtikultura yang ditanam di lahan yang relatif miring akan memiliki potensi erosi yang lebih tinggi dibandingkan dengan jenis tanaman lain (Saida et al., 2011)

Kondisi lahan pertanian yang demikian sangat perlu dilakukan tindakan konservasi sumber daya lahan yang mengupayakan agar lahan tersebut dapat dimanfaatkan secara bijaksana dan berkelanjutan eksistensinya. Menurut UU No. 32 tahun 2009 menyebutkan konservasi sumber daya alam adalah pengelolaan sumber daya alam untuk menjamin pemanfaatannya secara bijaksana serta berkesinambungan ketersediaannya dengan tetap memelihara dan meningkatkan kualitas nilai serta keanekaragamannya.

Salah satu jenis konservasi sumber daya alam adalah konservasi tanah. Menurut Rachman (2012), konservasi tanah sangat diperlukan untuk menjawab tantangan pengembangan lahan ke depannya karena kerusakan yang telah terjadi, sehingga dituntut adanya pengolahan ruang yang lebih bijaksana. Konservasi tanah memiliki peran yang sangat penting dalam prospek pengembangan lahan untuk mengatasi masalah kerusakan lahan, yang harapannya akan ada suatu pengelolaan lahan yang lebih baik (Zahro, 2011). Sehingga pada akhirnya akan tercipta suatu pembangunan yang berkelanjutan. Menurut UU No. 32 tahun 2009 pembangunan berkelanjutan adalah upaya sadar dan terencana yang 


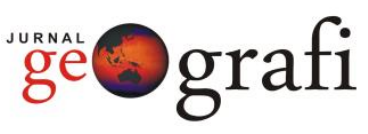

memadukan aspek lingkungan hidup, sosial, dan ekonomi ke dalam strategi pembangunan untuk menjamin keutuhan lingkungan hidup serta keselamatan, kemampuan, kesejahteraan, dan mutu hidup generasi masa kini dan generasi masa depan.

\section{METODE PENELITIAN}

Penelitian ini dilaksanakan di Kecamatan Merdeka Kabupaten Karo. Secara astronomis Kecamatan Merdeka terletak diantara $3^{\circ} 14^{\prime} 25^{\prime \prime} \mathrm{LU}-3^{\circ}$

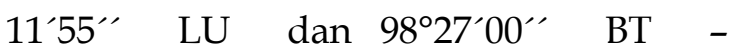
98 $31^{\prime \prime} 35^{\prime \prime}$ BT. Alat yang digunakan dalam penelitian ini yaitu GPS, Ring sampel, cangkul, pisau, plastik, dan alat tulis. Bahan yang digunakan yaitu citra DEM (peta kemiringan lereng), peta tutupan lahan, dan peta tanah. Teknik konservasi yang dilakukan adalah dengan teknik observasi lapangan dan observasi konstitusional. Data yang digunakan adalah data curah hujan, bulk density/ kerapatan masa tanah, tekstur tanah, corganik tanah, dan permeabilitas tanah.

Pengambilan sampel dilakukan dengan teknik purposive sampling (sampel bertujuan). Sampel yang diambil sebanyak 20 satuan lahan yang diperoleh dari hasil overlay peta penggunaan lahan, peta kemiringan lereng, dan peta jenis tanah Kecamatan Merdeka. Dari masingmasing satuan lahan tersebut dilakukan pengambilan data dari parameter seperti curah hujan, bulk density / kerapatan massa tanah, tekstur tanah, c-organik tanah, dan permeabilitas tanah. Dari data yang diperoleh tersebut dilakukan analisis curah hujan, analisis data tanah di laboratorium dan analisis peta dengan software ArcGIS. Hasil analisis data tersebut diolah kembali dengan metode prediksi erosi USLE.

Adapun analisis data dalam penelitian ini dilakukan dengan mengidentifikasi beberapa aspek berikut, yaitu:

\section{Laju erosi}

Laju erosi dapat diketahui dengan menggunakan metode USLE. Metode USLE adalah metode pendugaan erosi yang dikembangkan oleh Wischmeier dan Smith (1978) untuk memprediksi erosi di suatu tempat atau lahan. Adapun metode atau formula Universal Soil Loss Equation (USLE) di modelkan dengan Persamaan 1.

$\mathrm{A}=$ R.K.LS.C.P........................

(1)

Dimana :

A = Banyaknya tanah tererosi (ton ha/tahun)

$\mathrm{R}=$ faktor curah hujan dan aliran permukaan (Erosivitas) (MJ mm ha-1 hr-1 yr-1)

$\mathrm{K}=$ faktor erodibilitas tanah (ton ha $\mathrm{hr}$ MJ-1 mm-1 ha-1)

$\mathrm{LS}=$ faktor panjang dan kemiringan lereng (dimensionless)

$\mathrm{C}=$ faktor vegetasi penutup tanah dan pengelolaan tanaman (dimensionless)

$\mathrm{P}=$ faktor tindakan-tindakan khusus konservasi tanah (dimensionless)

\section{Laju Erosi yang masih dapat Ditoleransi}

Dalam menghitung laju erosi yang masih dapat ditoleransi diperoleh dari data umur guna tanah, kedalaman efektif tanah, faktor kedalaman tanah (jenis tanah) dan kerapatan massa tanah (Butar, 2013). Untuk menghitung nlai erosi yang masih dapat ditoleransi dipergunakan rumus Hammer (1981), pada persamaan 2. $\mathrm{T}=\frac{\text { de } x f d}{w} \times B D \times 10$

(2)

Catatan : $\mathrm{mm} \times$ Berat isi $\times$ Ton ha-1 $^{-1}$ tahun $^{-1}$

Dimana :

$\mathrm{T}=$ laju erosi yang dapat ditoleransi (mm / ha.tahun)

de $\quad=$ Kedalaman efektif tanah $(\mathrm{cm})$

$\mathrm{fd} \quad=$ Faktor kedalaman $\operatorname{tanah}=1$

$\mathrm{W}=$ Resource Life / Umur guna tanah $=400$ tahun (tahun)

$\mathrm{BD}=$ Bulk density (kerapatan massa) (gr $\left./ \mathrm{cm}^{3}\right)$ 


\section{Indeks Bahaya Erosi}

Indeks bahaya erosi merupakan indikator melihat besarnya erosi di suatu lahan dan pengaruhnya terhadap tingkat kelestarian produktivitas tanah (Ariyanto, 2008). Indeks bahaya erosi dapat diketahui dengan menggunakan Persamaan 3 dan kriteria tingkat bahaya erosi dapat dilihat pada Tabel 1.
$\mathrm{IBE}=\frac{A}{T}$.

Dimana :

IBE = Indeks bahaya erosi

A $\quad=$ Laju erosi $=$ R.K.LS.C.P (ton / ha / thn)

$\mathrm{T}=$ Erosi terbolehkan (ton / ha /

Tabel 1. Kriteria Indeks Bahaya Erosi

\begin{tabular}{cc}
\hline Nilai & Kriteria/ Rating IBE \\
\hline$<1,0$ & Rendah \\
$1,01-4,0$ & Sedang \\
$4,01-10,0$ & Tinggi \\
$>10,01$ & Sangat Tinggi \\
\hline
\end{tabular}

Sumber : Hammer, (1981)

\section{HASIL DAN PEMBAHASAN \\ Erosi USLE (R.K.LS.C.P)}

Indeks erosi dari ke 5 (lima) faktor yang telah diuraikan sebelumnya akan menjadi parameter untuk mengetahui laju erosi di Kecamatan Merdeka dengan metode pendugaan erosi USLE. Hasil perhitungan berbagai parameter indeks erosi tersebut disajikan pada Tabel 2.

Tabel 2 (dua) menunjukkan bahwa laju erosi terbesar terjadi pada penggunaan lahan tegalan dengan satuan lahan AIVUs serta dengan laju erosi sebesar 1.683,317 ton /ha/thn. Faktor penyebab nilai laju erosi yang tinggi dikarenakan satuan lahan ini berada pada kelerengan 25 - 45\% dengan nilai indeks kelerengan sebesar 9,50. Hal tersebut diasumsikan bahwa jika semakin besar kemiringan lereng maka semakin besar pula erosinya. Hal ini terkait dengan energi kinetik hempasan air hujan ke tanah yang bertambah besar seiring bertambahnya kemiringan lereng Bukhari, (2014). Untuk mengantisipasi atau meminimalisirkan laju erosi di lahan tersebut perlu dilakukan upaya praktek konservasi untuk menekan laju erosi seperti melakukan penanaman dengan lajur memotong lereng atau searah dengan garis kontur. Selain itu juga bisa dilakukan pemilihan jenis tanaman yang memiliki nilai faktor (C) yang kecil sehingga dapat memperkecil laju erosi.

\section{Erosi Terbolehkan Kecamatan Merdeka}

Adapun besar nilai erosi yang masih dapat ditoleransi dipengaruhi oleh beberapa faktor seperti faktor kedalaman tanah, solum tanah, kerapatan massa tanah / bulk density serta umur guna tanah dapat dilihat pada Tabel 2. Untuk mengetahui besarnya nilai erosi terbolehkan dalam tiap satuan lahannya diperlukan data-data seperti data yang telah disebutkan diatas.

Tabel 2 (dua) menunjukkan bahwa nilai erosi terbolehkan di Kecamatan Merdeka dimulai dari 6,56 ton/ha/tahun dengan luas 5,04 ha $(0,16 \%)$ sampai dengan 36,96 ton/ha/tahun dengan luas lahan 9,24 ha $(0,29 \%)$. Adapun nilai erosi terbolehkan tertinggi terjadi pada satuan lahan IIBl dengan jenis penggunaan lahan semak belukar sedangkan nilai erosi terendah terjadi pada satuan lahan $\mathrm{IVHz}$ dengan jenis penggunaaan lahan hutan sekunder. 
Tabel 2. Rekap Indeks Erosi di Berbagai Satuan Lahan Kecamatan Merdeka

\begin{tabular}{|c|c|c|c|c|c|c|c|c|c|c|c|c|}
\hline \multirow[t]{2}{*}{ No } & \multirow{2}{*}{$\begin{array}{l}\text { Satuan } \\
\text { Lahan }\end{array}$} & \multicolumn{5}{|c|}{ Nilai Faktor-Faktor Erosi } & \multirow{2}{*}{$\begin{array}{c}\text { Bahaya } \\
\text { Erosi } \\
\text { (A) }\end{array}$} & \multirow{2}{*}{$\begin{array}{c}\text { Erosi } \\
\text { Terbolehkan } \\
\text { (T) }\end{array}$} & \multirow[t]{2}{*}{ IBE } & \multirow{2}{*}{$\begin{array}{c}\text { Kelas } \\
\text { IBE/TBE }\end{array}$} & \multicolumn{2}{|c|}{ Luas } \\
\hline & & $\mathrm{R}$ & K & LS & $\mathrm{C}$ & $\mathrm{P}$ & & & & & $\mathrm{Ha}$ & $\%$ \\
\hline 1 & AIKk & $1.685,609$ & 0,352 & 0,25 & 0,2 & 1,00 & 29,667 & 15,3 & 1,94 & $S$ & 51,01 & 1,57 \\
\hline 2 & $\mathrm{IIHz}$ & $1.685,609$ & 0,383 & 0,25 & 0,2 & 1,00 & 32,279 & 21,2 & 1,52 & $S$ & 115,36 & 3,57 \\
\hline 3 & IIBl & $1.685,609$ & 0,314 & 0,25 & 0,3 & 1,00 & 39,696 & 36,96 & 1,07 & $S$ & 9,24 & 0,29 \\
\hline 4 & AIUs & $1.685,609$ & 0,275 & 0,25 & 0,7 & 0,50 & 40,560 & 24,25 & 1,67 & $S$ & 605,27 & 18,73 \\
\hline 5 & IIIKk & $1.685,609$ & 0,253 & 1.20 & 0,2 & 0,40 & 40,940 & 24 & 1,71 & $S$ & 49,93 & 1,55 \\
\hline 6 & IIIHz & $1.685,609$ & 0,359 & 1,20 & 0,2 & 1,00 & 145,232 & 23,98 & 6,06 & $\mathrm{~T}$ & 216,46 & 6,70 \\
\hline 7 & IIIBI & $1.685,609$ & 0,234 & 1,20 & 0,3 & 1,00 & 141,996 & 13,75 & 10,33 & ST & 23,07 & 0,71 \\
\hline 8 & AIIUs & $1.685,609$ & 0,314 & 1,20 & 0,7 & 0,75 & 333,447 & 24,74 & 13,48 & ST & 673,65 & 20,85 \\
\hline 9 & AIIIKk & $1.685,609$ & 0,434 & 4,25 & 0,2 & 0,40 & 248,728 & 8,43 & 29,51 & ST & 24,60 & 0,76 \\
\hline 10 & $\mathrm{IIIIHz}$ & $1.685,609$ & 0,306 & 4,25 & 0,2 & 1,00 & 438,427 & 24,01 & 18,26 & ST & 246,69 & 7,63 \\
\hline 11 & IIIIBl & $1.685,609$ & 0,171 & 4,25 & 0,3 & 1,00 & 367,505 & 14,57 & 25,22 & ST & 31,89 & 0,99 \\
\hline 12 & AIIIUs & $1.685,609$ & 0,183 & 4,25 & 0,7 & 0,40 & 367,075 & 12,8 & 28,68 & ST & 324,21 & 10,03 \\
\hline 13 & AIVKk & $1.685,609$ & 0,200 & 9,50 & 0,2 & 0,40 & 256,213 & 17,75 & 14,43 & ST & 3,04 & 0,09 \\
\hline 14 & IIVHz & $1.685,609$ & 0,105 & 9,50 & 0,2 & 1,00 & 336,279 & 23,37 & 14,39 & ST & 210,43 & 6,51 \\
\hline 15 & IIVBl & $1.685,609$ & 0,299 & 9,50 & 0,3 & 1,00 & $1.436,392$ & 10,82 & 132,75 & ST & 35,61 & 1,10 \\
\hline 16 & AIVUs & $1.685,609$ & 0,292 & 9,50 & 0,4 & 0,90 & $1.683,317$ & 23,97 & 70,23 & ST & 189,41 & 5,86 \\
\hline 17 & IVKk & $1.685,609$ & 0,282 & 12,00 & 0,2 & 0,40 & 456,328 & 6,56 & 69,56 & ST & 5,04 & 0,16 \\
\hline 18 & $\mathrm{IVHz}$ & $1.685,609$ & 0,390 & 12,00 & 0,2 & 1,00 & $1.577,730$ & 25,88 & 60,96 & ST & 329,40 & 10,19 \\
\hline 19 & IVBl & $1.685,609$ & 0,245 & 12,00 & 0,3 & 1,00 & $1.486,707$ & 6,81 & 218,31 & ST & 32,08 & 0,99 \\
\hline 20 & AVUs & $1.685,609$ & 0,239 & 12,00 & 0,2 & 0,40 & 386,746 & 11,22 & 34,47 & ST & 54,64 & 1,69 \\
\hline
\end{tabular}

Sumber : Hasil Analisis, (2017)

Faktor yang mempengaruhi erosi terbolehkan adalah kedalaman efektif tanah (solum tanah), bulk density (berat masa tanah), dan resource life (umur guna tanah). Namun yang paling mempengaruhi besar kecilnya erosi terbolehkan adalah faktor solum tanah dan bulk density.

Faktor kedalaman efektif tanah (solum tanah) sangat mempunyai andil yang signifikan dalam besar kecilnya erosi terbolehkan pada suatu lahan. Semakin besar atau dalam solum tanah maka akan semakin memperbesar nilai erosi terbolehkan di suatu lahan. Dengan kata lain semakin dalam solum tanah akan memperkecil terjadinya erosi di suatu lahan. Hal itu dapat terjadi karena jika suatu lahan memiliki solum tanah yang dalam akan mengakibatkan aliran air yang ada dipermukaan tanah mempunyai tempat yang memadai untuk terserap ke dalam tanah, sehingga erosi yang terjadi bisa terminimalisirkan. Sebagai contoh pada satuan lahan IVKk yang memiliki nilai erosi terbolehkan paling kecil yaitu sebesar 6,56 ton/ha/tahun hal ini dikarenakan solum tanah di satuan lahan ini adalah yang sangat dangkal yaitu 25 $\mathrm{cm}$. Jika dibandingkan dengan satuan lahan IIBl yang memiliki nilai erosi terbolehkan yang tertinggi yaitu 36,96 ton/ha/tahun memiliki solum tanah yang dalam yaitu $88 \mathrm{~cm}$.

Bulk density (berat masa tanah) juga sangat mempengaruhi nilai dari erosi terbolehkan. Bulk density (berat masa tanah) yang besar akan mengakibatkan nilai erosi terbolehkan juga besar, sebaliknya jika Bulk density kecil akan mengakibatkan nilai erosi terbolehkan juga akan kecil. Seperti terlihat pada satuan lahan IVKk yang memiliki nilai Bulk density yaitu sebesar 1,05, lebih kecil dari satuan lahan IIBl dengan nilai sebesar 1,68. Sehingga dapat disimpulkan bahwa nilai erosi terbolehkan berbanding lurus dengan besar kecilnya bulk density.

Erosi terbolehkan atau erosi yang masih bisa ditoleransi jika dibandingkan dengan nilai laju erosi dapat menjadi acuan untuk konservasi lahan pada suatu kawasan tertentu.

\section{Indeks Bahaya Erosi Kecamatan Merdeka}


Indeks bahaya erosi di Kecamatan Merdeka dapat diperoleh dengan menggunakan rumus Persamaan 3 (tiga). Indeks bahaya erosi dapat diketahui dengan membandingkan nilai laju erosi dengan nilai erosi terbolehkan. Nilai indeks bahaya erosi di Kecamatan Merdeka dapat dilihat pada Tabel 2. Adapun sebaran indeks bahaya erosi dapat dilihat pada Gambar 1.

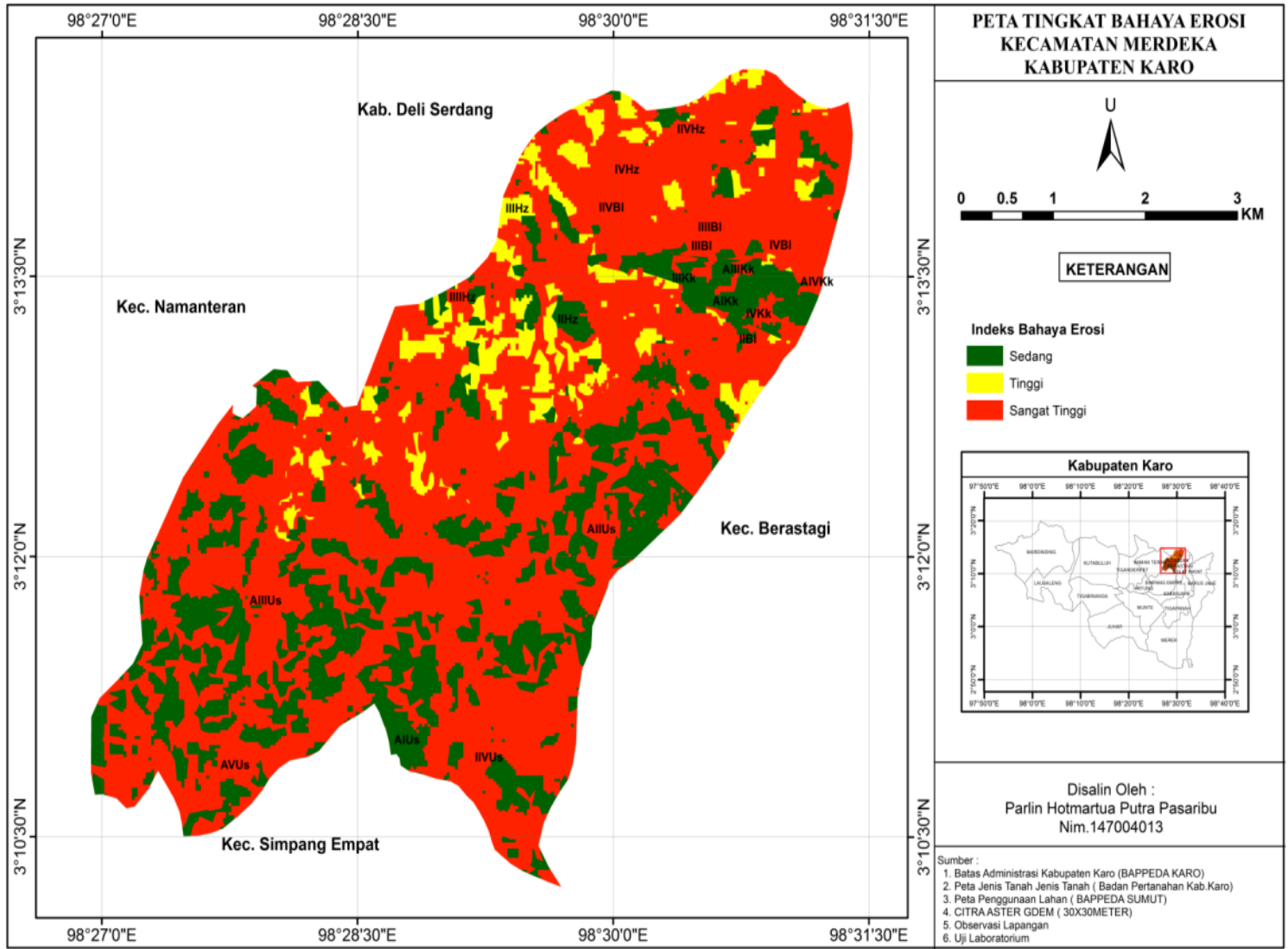

Gambar 1. Peta Tingkat Bahaya Erosi Kecamatan Merdeka

Tabel 2 (dua) menunjukkan bahwa indeks erosi di Kecamatan Merdeka berkisar antara 1,07 ton/ha/tahun sampai 218,31 . Indeks bahaya erosi terendah terdapat pada satuan lahan IIBl dengan indeks bahaya erosi 1,07 dengan jenis penggunaan lahan semak belukar dan dengan luas 9,24 ha $(0,29 \%)$. Satuan lahan ini memiliki indeks erosi rendah artinya memiliki kerentanan terhadap erosi yang juga rendah. Dengan kata lain memiliki erosi yang kecil dikarenakan satuan lahan ini memiliki laju erosi yang sangat rendah yaitu 39,696 ton/ha/tahun ditambah lagi dengan erosi terbolehkan yang tinggi yaitu 36,96. Hal tersebut akan mengakibatkan indeks erosi yang juga kecil karena indeks erosi tersebut didapat dari perbandingan laju erosi dengan erosi terbolehkan (Firdaus, 2016).

Indeks bahaya erosi tertinggi terdapat pada satuan lahan IVBl dengan nilai indeks bahaya erosi 218,31 dan dengan luas lahan 32,08 ha $(0,99 \%)$. Satuan lahan tersebut memiliki indeks erosi yang tinggi dipengaruhi oleh nilai laju erosi yang tinggi yaitu 1.486,707 ton/ha/tahunsedangkan erosi terbolehkannya sangat kecil yaitu 6,81 sehingga mengakibatkan nilai indeks bahaya erosi di satuan lahan ini menjadi sangat tinggi.

Kelas indeks bahaya erosi di Kecamatan Merdeka ada 3 (tiga) kategori yaitu : (1) Sedang, merupakan indeks bahaya erosi dengan nilai $1,1-4,0$; (2) Tinggi, merupakan indeks bahaya erosi 
dengan nilai 4,01-10,0; (3) Sangat tinggi, merupakan indeks bahaya erosi dengan nilai $>10,01$. Berdasarkan hasil tersebut dapat disimpulkan bahwa ketika nilai indeks erosi semakin besar maka semakin besar pulalah tingkat bahaya erosinya fatmaraga (2013). Nilai indeks bahaya erosi di Kecamatan Merdeka dapat dilihat pada Tabel 2.

\section{Arahan Atau Prioritas Konservasi Tanah Kecamatan Merdeka}

Arahan atau prioritas konservasi tanah dapat ditentukan berdasarkan nilai indeks bahaya erosi, faktor penyebab erosi dan tipe tutupan lahan. Untuk mengetahui lebih jelas bagaimana arahan konservasi tanah Kecamatan Merdeka dapat dilihat pada Tabel 2 dan Gambar 2.

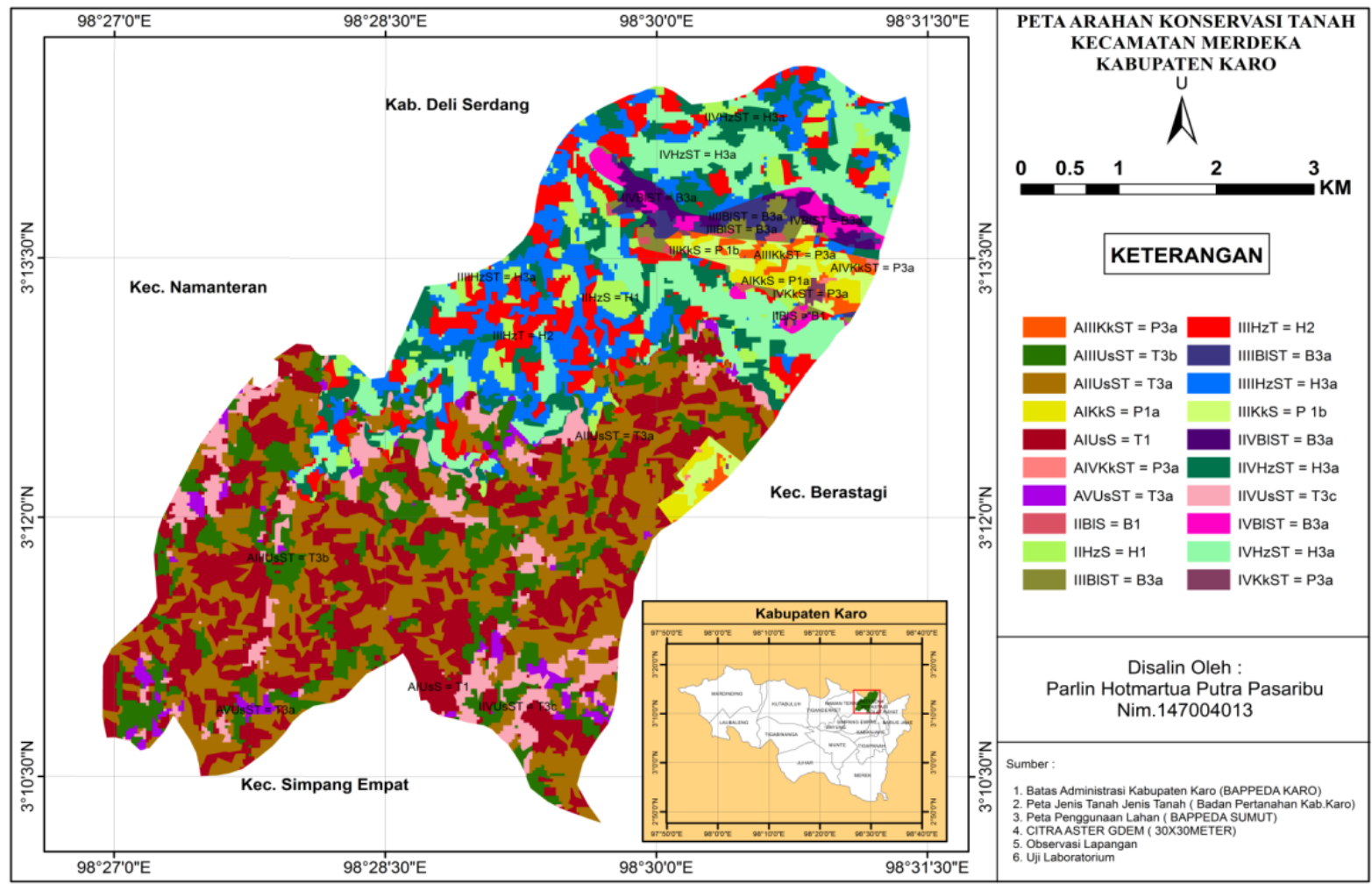

Gambar 2. Peta Arahan Konservasi Tanah Kecamatan Merdeka

Konservasi tanah merupakan upaya mengelola tanah dengan cara memperbaiki, memelihara dan meningkatkan daya guna tanah sesuai dengan peruntukannya. Konservasi tanah dilakukan dengan tujuan meminimalisirkan erosi sehingga produktivitas lahan meningkat (Meylina, 2015). Berikut ini merupakan uraian mengenai arahan konservasi tanah pada berbagai kategori tingkat bahaya erosi di Kecamatan Merdeka.

\section{Tingkat Bahaya Erosi Sedang}

Pada kategori ini yang menjadi faktor penyebab erosi yaitu seperti bahan organik rendah, nilai erodibilitas sedang sampai yang agak tinggi, lahan tanpa praktek konservasi, dan vegetasi penutup yang jelek.

\section{a. Penggunaan Lahan Permukiman}

Penggunaan lahan permukiman di satuan lahan AIKk dan IIIKk sendiri dianjurkan untuk dikonservasi secara vegetatif yaitu dengan penanaman tanaman pekarangan di sekitar rumah. Tanaman pekarangan sendiri merupakan tanaman tahunan dan tanaman semusim yang sering dikombinasikan dengan pemeliharaan ternak. Jenis tanaman yang dianjurkan untuk ditanam di sekitar wilayah rumah adalah tanaman semusim. Hal ini dilakukan dengan pertimbangan 
bahwa di satuan lahan AIKk dan IIIKk memiliki kemiringan lereng yang kecil yaitu $0-8 \%$ dan paling tinggi hanya mencapai $8-15 \%$. Tanaman penutup tanah seperti rumput berfungsi sebagai penahan percikan air hujan dan aliran permukaan disekitar rumah.

\section{b. Penggunaan lahan Hutan Sekunder}

Upaya konservasi tanah yang disarankan untuk wilayah ini (satuan lahan $\mathrm{IIHz}$ ) adalah dengan melakukan pengkayaan tanaman keras, pengkayaan dengan pohon serbaguna dan kebun campuran. Pengkayaan tanaman keras merupakan upaya untuk menambah komoditas vegetasi berupa tanaman tahunan yang mempunyai perakaran yang kuat. Hal tersebut dimaksudkan untuk menahan aliran permukaan dan memperkuat perakaran untuk menahan terjadinya longsor. Penanaman pohon serbaguna selain berfungsi mencegah longsor, aliran permukaan dan melebatkan tutupan lahan hutan, tanaman tersebut juga dapat memberi keuntungan ekonomis bagi masyarakat karena memiliki nilai jual yang tinggi. Kebun campuran merupakan komponen tanaman hutan dan tanaman tahunan lainnya yang sengaja ditanam di areal hutan sekunder seperti petai, jengkol, aren, meilinjo, dan buah-buahan dan kadang juga disertai dengan jenis tanaman semusim yang memperkaya vegetasi di kawasan hutan tersebut bahkan memberikan nilai ekonomis bagi masyarakat setempat.

\section{c. Penggunaan Lahan Semak Belukar}

Salah satu upaya meningkatkan nilai manfaat penggunaan lahan ini (satuan lahan IIBl) adalah dengan cara penghutanan kembali kawasan ini. Penghutanan kembali kawasan ini bertujuan untuk meningkatkan jumlah vegetasi permanen sehingga kaya akan komoditas tanaman. Manfaat lainnya adalah untuk meningkatkan perekonomian warga setempat yang sering memanfaatkan tanaman hutan untuk keperluan hidupnya.

\section{d. Penggunaan Lahan Tegalan}

Konservasi vegetatif pada penggunaan lahan tegalan ini (satuan lahan AIUs) yaitu penanaman dengan cara tumpang sari dan penambahan mulsa organik dengan tujuan untuk mengurangi limpasan atau aliran permukaan sehingga membantu tanaman tegalan (sayuran) tersebut untuk tidak tergerus oleh limpasan air hujan. Adapun mulsa organik tersebut merupakan bahan utama dari sumber organik tanah pertanian yang membantu meminimalisirkan erosi. Bahkan bahan organik tersebut berpengaruh terhadap peningkatan kualitas sifat tanah seperti penyimpanan air, resapan air dan agregasi partikel (Erfandi, 2014).

\section{Tingkat Bahaya Erosi Tinggi}

Upaya konservasi pada satuan lahan IIIHz dengan nilai 4,01-10,0 dan dengan faktor penyebab erosi yaitu seperti nilai erodibilitas agak tinggi, dan lahan tanpa adanya praktek konservasi dapat dilakukan dengan pengkayaan kembali hutannya dengan penanaman tanaman pohon serbaguna (multipurpose trees) yaitu jenis tanaman serbaguna yang memiliki perakaran yang kuat untuk menahan erosi seperti pohon manggis, aren, asam glugur, durian dan lain sebagainya. Selain itu perlu ditambahkan dengan tanaman semusim sebagai tanaman tambahan untuk menutup areal kosong di kawasan hutan ini. Hal tersebut dimaksudkan untuk mencegah aliran permukaan dan bahaya longsor lahan serta memperkuat perakaran.

\section{Tingkat Erosi Sangat Tinggi}

Pada kategori ini yang menjadi faktor penyebab erosi yaitu seperti bahan organik rendah, nilai erodibilitas agak tinggi, lahan tanpa praktek konservasi, vegetasi penutup jelek, lereng agak curam sampai yang sangat curam. 


\section{a. Penggunaan Lahan Permukiman}

Adapun konservasi vegetatif yang dapat dilakukan pada tutupan lahan permukiman (satuan lahan AIIIKk, AIVKk, dan IVKk) adalah dengan melakukan penanaman tanaman pekarangan disekitar lingkungan rumah seperti pepohonan yang memiliki perakaran yang kuat. Pembuatan saluran pembuangan air pada kawasan ini perlu dilakukan karena kawasan permukiman di kategori ini memiliki kemiringan lereng yang mencapai angka $>45 \%$. Upaya konservasi lahan seperti pembuatan saluran air ini berfungsi untuk mengalirkan air pada satu aliran sehingga mencegah terjadinya limpasan permukaan yang tidak teratur sehingga menimbulkan dampak yang buruk.

\section{b. Penggunaan lahan Hutan Sekunder}

Selain melakukan upaya pengkayaan tanaman keras, pengkayaan pohon serbaguna, penaman kebun campuran pada satuan lahan $\mathrm{IIIIHz}$, IIVHz, hal yang perlu dilakukan lagi adalah penanaman menurut kontur, kebun campuran tertutup oleh vegetasi permanen, dan tanaman penutup tanah. Penanaman menurut kontur merupakan pola penanaman yang pada praktiknya mengikuti garis kontur bumi atau dengan kata lain memotong arah lereng. Hal tersebut dilakukan dengan tujuan untuk memperkecil aliran permukaan, meningkatkan infiltrasi air, dan mencegah longsor. Penanaman pada kebun campuran dapat berupa tanaman keras dan tahunan yang memiliki usia yang relatif lama dengan daya tahan yanag kuat. Hal ini dimaksudkan agar kawasan hutan tersebut dapat bertahan dengan waktu yang lama dan dapat memberi manfaat dalam masa waktu yang relatif lama bagi warga setempat. Tanaman penutup tanah yang diperlukan di kawasan hutan yaitu rerumputan. Hal tersebut dilakukan agar kawasan hutan tersebut tertutup rapat oleh vegetasi sehingga aliran permukaan dan longsor lahanpun akan sangat jarang kemungkinan terjadi di kawasan ini.

\section{c. Penggunaan Lahan Semak Belukar}

Penggunaan lahan semak belukar pada kategori ini (satuan lahan IIIB1, IIIIB1, IIVB1, dan IVB1) perlu dilakukan konservasi tanah berupa penanaman tanaman menurut kontur, talun tertutup vegetasi permanen dan tanaman penutup tanah. Penanaman menurut kontur bertujuan untuk mengurangi aliran permukaan sehingga menahan laju erosi, sehingga cara ini sangat penting untuk dilakukan. Menurut Giyanti, (2016), mendukung pernyataan diatas bahwa kawasan dengan jenis tutupan lahan semak belukar dapat dikonservasi dengan melakukan penanaman menurut kontur dan pertanaman dalam strip. Talun tertutup vegetasi permanen adalah teknik konservasi tanah yang dilakukan dengan cara menanam tanaman semusim atau tahunan yang bersifat rapat antar vegetasi. Hal tersebut dimaksudkan untuk mencegah limpasan permukaan di dasar semak belukar karena dengan rapatnya vegetasi akan menghalangi jatuhnya limpasan air hujan ke permukaan tanah.

\section{d. Penggunaan Lahan Tegalan}

Salah satu contoh upaya konservasi pada penggunaan lahan tegalan pada satuan lahan AIIUs, AIIIUs, AIVUs, AVUs adalah penanaman menurut kontur. Hal ini dilakukan mengingat topografi di kawasan ini memiliki kemiringan lereng yang besar mulai dari landai sampai yang sangat curam yaitu $8-15 \%$ hingga $>45 \%$. Kemiringan lereng yang curam ditambah tutupan lahan tegalan (sayuran) merupakan faktor utama yang menyebabkan tingkat bahaya erosi yang tinggi pada lahan seperti ini sehingga harus dilakukan tindakan pencegahan berupa penanaman menurut kontur. Hal tersebut didukung oleh Sutrisno (2013), yang menyatakan bahwa konservasi tanah secara mekanik dapat membantu meminimalisirkan erosi dengan mengatasi 
dampak buruk kemiringan dan panjang lereng yang besar.

Namun ada pengecualiaan untuk satuan lahan AIVUs. Satuan lahan ini ditumbuhi oleh jenis tanaman kentang. Jenis tanaman kentang tidak akan tumbuh baik dengan teknik konservasi mengikuti atau searah lereng karena jika hal tersebut terjadi maka kentang tersebut akan busuk karena aliran airnya akan tertahan pada tiap bendengan-bendengan yang dibuat. Oleh sebab itu, terkhusus untuk satuan lahan AIVUs akan dilakukan penanaman searah lereng atau berlawanan dengan garis kontur.

Metode teras bangku merupakan cara yang wajib diterapkan pada kawasan ini karena sangat tepat untuk mengurangi kecepatan aliran permukaan sehingga dapat mengurangi kerusakan tanah. Teras bangku yang telah dibuat ada baiknya di kombinasikan dengan penanaman vegetasi tanaman keras atau tahunan sehingga memaksimalkan pencegahan terhadap limpasan permukaan bahkan bahaya longsor lahan. Lathifah (2013), menambahkan bahwa limpasan permukaan pada lereng yang curam yang memicu erosi yang signifikan dapat diatasi dengan mengimbanginya dengan tegakan vegetasi tinggi dan vegetasi penutup tanah sehingga mampu menghambat laju limpasan air.

\section{KESIMPULAN}

1) Laju erosi terendah di Kecamatan Merdeka terdapat pada penggunaan lahan permukiman dengan satuan lahan AIKk yaitu sebesar 29,667 ton/ha/tahun, sedangkan nilai laju erosi tertinggi terdapat pada penggunaan lahan tegalan dengan satuan lahan AIVUs yaitu sebesar $1.683,317$ ton/ha/tahun.

2) Nilai erosi terbolehkan terbesar terdapat pada penggunaan lahan semak belukar yaitu sebesar 36,96 ton/ha/tahun dengan satuan lahan IIBl. Sedangkan erosi terbolehkan terkecil terdapat pada penggunaan lahan permukiman yaitu sebesar 6,56 ton/ha/tahun dengan satuan lahan IVKk.

3) Indeks bahaya erosi tertinggi terdapat pada penggunaan lahan semak belukar yaitu 218,31 ton/ha/tahun dan berada pada satuan lahan IVB1. Indeks bahaya erosi terendah terdapat pada penggunaan lahan semak belukar yaitu 1,07 ton/ha/tahun dan berada pada satuan lahan IIBl.

4) Teknik konservasi tanah yang disarankan untuk tipe penggunaan lahan tegalan yaitu tumpang sari, mulsa organik (vegetatif), penanaman sejajar kontur, teras gulud, teras bangku, dan saluran pengelak (mekanik). Teknik konservasi tanah yang disarankan untuk tipe penggunaan lahan semak belukar yaitu penghutanan kembali, talun, tanaman penutup tanah (vegetatif), penanaman menurut kontur (mekanik). Teknik konservasi tanah yang disarankan untuk tipe penggunaan lahan hutan sekunder yaitu pengkayaan tanaman keras dan pohon serbaguna, kebun campuran, tanaman penutup tanah (vegetatif), dan penanaman menurut kontur (mekanik).

\section{DAFTAR PUSTAKA}

Anwar, R.M., Pudyono., Sahiruddin, M. 2009. Penanggulangan Erosi Secara Struktural Pada Daerah Aliran Sungai Bango. Jurnal Rekayasa Sipil : 3 (1) : 51

Ariyanto, D. P., \& Widijanto, H. (2013). Kajian Klasifikasi Bahaya Erosi dengan Sistem Informasi Geografi di Daerah Hulu Waduk Sempor, Gombong. Sains Tanah-Journal of Soil Science and Agroclimatology, 5(2), 121-128.

BPS (Badan Pusat Statistik). 2016. Kecamatan Merdeka Dalam Angka. Kabanjahe : Pemerintah Kabupaten Karo 


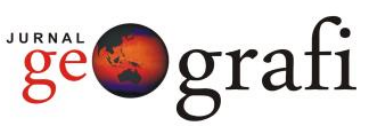

Bukhari, I., Lubis, K. S., \& Lubis, A. (2014). Pendugaan Erosi Aktual Berdasarkan Metode USLE Melalui Pendekatan Vegetasi, Kemiringan Lereng dan Erodibilitas di Hulu Sub DAS Padang. Agroekoteknologi, 3(1).

Butar, M. J. O. B., Lubis, K. S. L. K. S., \& Sitanggang, G. S. G. (2013). Pendugaan Erosi Tanah di Kecamatan Raya Kabupaten Simalungun Berdasarkan Metode USLE. Agroekoteknologi, 1(2).

Erfandi, D. (2014). Strategi Konservasi Tanah Dalam Sistem Pertanian Organik Tanpa Olah Tanah. Prosiding seminar nasional pertanian organik

Fatmaraga, M. A. (2013). Pemanfaatan Citra Penginderaan Jauh Multi Temporal Untuk Kajian Tingkat Bahaya Erosi (Kasus di Sub DAS Karang Mumus, Kalimantan Timur) (Doctoral dissertation, Universitas Gadjah Mada).

Firdaus, G., Haridjaja, O., \& Tarigan, S. D. (2016). Analisis Respon Hidrologi terhadap Penerapan Teknik Konservasi Tanah di Sub DAS Lengkong Menggunakan Model SWAT. Jurnal Tanah dan Lingkungan, 16(1), 16-23.

Giyanti, F. D. (2016). Identifikasi Tingkat Bahaya Erosi Berbasis Sistem Informasi Geografis (SIG) Pada Sub Daerah Aliran Sungai (DAS) Riam Kanan. Jurnal Purifikasi, 14(1), 1-10.

Hammer, W.I. 1981. Soil Conservation Consultant Report Center For Soil. Research. LPT. Bogor Indonesia

Lathifah, D. H., \& Yunianto, T. (2013). Hubungan Antara Fungsi Tutupan Vegetasi dan Tingkat Erosi DAS Secang

Kabupaten
Available at http://jurnal.unimed.ac.id/2012/index.php/geo e-ISSN: 2549-7057 | p-ISSN: 2085-8167

Kulonprogo. Jurnal

Bumi Indonesia, 2(1).

Makhrawie. 2012. Evaluasi Kerusakan Tanah Untuk Produksi Biomassa Pada Areal Lahan Kering di Kota Tarakan. Jurnal Media Sains : 4 (2) : 185

Meylina,E., Wahyuningsih,S., \& Pudjojono, M. (2015). Estimasi Tingkat Erosi Pada Sistem Tumpangsari Kopi - Tanaman Semusim Menurut Metode MUSLE (Modified Universal Soil Loss Equation) di Desa Pace Kecamatan Silo Kabupaten Jember. Teknologi Pertanian. 1(1).

Rachman, M. 2012. Konservasi Nilai Dan Warisan Budaya. Jurnal Konservasi Indonesia: 1 (1) : 31-38

Saida, Sabihan, S., Sutjahjo H,S. (2011). Analisis Keberlanjutan Usaha Tani Holtikultura Sayuran Pada Lahan Berlereng Di Hulu DAS Jeneberang, Sulawesi Selatan. Jurnal Matematika, Sains, dan Teknologi: 12 (2) : 101-102.

Sutrisno, J., Sanim, B., Saefuddin, A., \& Sitorus, S. R. (2013). Arahan Kebijakan Pengendalian Erosi dan Sedimentasi di Sub Daerah Aliran Sungai Keduang Kabupaten Wonogiri.Sains Tanah-Journal of Soil Science and Agroclimatology, 8(2), 105-118.

Wischmeier W.H., and D.D. Smith. 1978. Predicting Rainfall Erosion Losses: Aguide to Conservation Planning. USDA Handbook No. 537. Washington DC.

Yudhistira., Hidayat, K.W., Hadiyarto, A. 2011. Kajian Dampak Kerusakan Lingkungan Akibat Kegiatan Penambangan Pasir di Desa Keningar Daerah Kawasan 
Gunung Merapi. Jurnal Ilmu Lingkungan :

$9(2): 77$

Zahro, F., Usman, F., Wardhani, K.D. 2011. Arahan Fungsi Lahan Berdasarkan Pendekatan Konservasi Tanah kawasan Pesisir Utara Jawa Timur Kecamatan Ujung Pangkah Kabupaten Gresik. Jurnal Tata Kota dan Daerah : 3 (1): 34 